\title{
Investigating the Impact of Balanced Scorecard on Performance of Business: A study based on the Banking Sector of Pakistan
}

\author{
Muhammad Tariq \\ Institute of Business and Technology \\ Karachi, Pakistan \\ Arslan Ahmed \\ Iqra University \\ Karachi, Pakistan \\ Syed Kashif Rafi \\ Institute of Business and Technology \\ Karachi, Pakistan \\ Shuaib Ahmed \\ Institute of Business \& Technology (IBT) \\ Karachi \\ Pakistan
}

\begin{abstract}
Purpose: This study is made with objective to investigate the practicability and effectiveness of setting and implementing the Balance Score Card (BSC) in improving the overall performance of an organization.

Methodology/Sampling: The Multiple Regression has been deployed to analyze the survey results. The BSC model has been formulated on the bases of five Perspectives: financial, internal control, learning and growth, customers and Vision and Strategy.

Findings: The findings of the study suggest that implementation of Balance scorecard models in Banks provide favorable outcomes in perspectives of financial, internal control, learning and growth and customers. Financial Perspective of BSC greatly influences the Banks' performance. Further, setting the standards for customer preferences pursue the customers to be loyal with Bank.

Practical Implications: The outcome of this study provides a framework and importance of application of Balance Score Card in Banking Industry. The other Industry may also take benefit of this studv.
\end{abstract}

Keywords: Internal Control, Performance Measurement, Efficiency.

JEL Classification: M10, M16.

\footnotetext{
* The material presented by the authors does not necessarily portray the viewpoint of the editors and the management of the Institute of Business \& Technology (IBT).

* Muhammad Tariq: Muhammad.tariq1985@gmail.com

* Arslan Ahmed: Arslan courage@ gmail.com

* Shuaib Ahmed: shoaib.ahmed@ibt.edu.pk

* Syed Kashif Rafi: kashifrafi@ibt.edu.pk

* Shuaib Ahmed: shoaib.ahmed@ibt.edu.pk

CJMSS is published by the Institute of Business and Technology (IBT). Main Ibrahim Hydri Road, Korangi Creek, Karachi-75190, Pakistan.
} 


\section{INTRODUCTION}

What is measured in the Firms is the thing that the senior executives comprehend that their conglomeration's estimation framework decidedly influences the conduct of chiefs and workers. Executives likewise grasp that universal fiscal bookkeeping measures like rate of return and profit for every portion can give deluding signs for ceaseless change and enhancement -exercises today's focused surroundings requests. The accepted fiscal execution measures worked well for the mechanical period, however they are out of go with the abilities and capabilities organizations are attempting to ace today. As chiefs and scholarly specialists have tried to cure the deficiency of current execution estimation frame works, some have kept tabs on making fiscal measures more applicable. While on the other side it has been stated that forget the fiscal measures; enhance operational measures like process duration and deformity rates. The fiscal effects will take after such as the administrators ought not to need to pick between monetary and operational measures. In watching and working with numerous organizations, it has discovered that senior executives don't depend on one set of measures to the prohibition of the other. The senior executives understand that no single measure can give an acceptable execution target or center consideration on the basic territories of the business and directors need an adjustment (Malmi, 2001). Balance scorecard (BSC) may be stated as an execution instrument and a semi-standard organized report, backed by configuration techniques and mechanization devices that might be utilized by directors to stay informed regarding the execution of exercises by the staff inside their control and to screen the outcomes emerging from these movements (Banker, Chang, \&Pizzini, 2004). Since its unique incarnation in the early 1990s as an execution estimation apparatus, the BSC has advanced to turn into a successful methodology execution structure. It's currently seen as a discriminating establishment in a comprehensive technique execution transform that, other than helping conglomerations expressive system in actionable terms, gives a guide for procedure execution, for assembling and arranging executives and representatives, and making methodology a persistent methodology. Maltz, Shenhar and Reilly (2003) made study where the measuring system was testes in some firms to check the significance. The study suggested that performance was improved with usage of the designed measuring system for performance.

\subsection{Problem Statement}

The objective of the study is to investigate the impact of Implementation of the Balanced Scorecard (BSC) and its link with the performance. The study discusses five perspectives of the measurement systems which are included the proposed BSC. The perspectives include financial, strategy, internal control and customer. This study shall investigate the impact of Implementation of the Balanced Scorecard (BSC) and its link with the performance

\section{LITERATURE REVIEW}

Amaratunga, Haigh, Sarshar and Baldry (2002) made study on the effectiveness of the Balance Score Card (BSC). The study was conducted over the efficiency in organization regarding financial and process prospects. The respondents of the survey were key professionals in different organizations. The study revealed that well balanced scorecard (BSC) can be a popular management construction for the description regarding organizational efficiency. It was suggested that key pinpoints for the BSC strategy as a means regarding 
deploying organizing direction, speaking anticipations, and calculating progress to arranged objectives.

Neely (1999) made comprehensive study on Performance Measurement. The design of the study was such that employees were initially given proper instructions and guidelines and then each employee was properly supervised. The performance was controlled through well-designed tools and finally data related to key performance indicators, success factors and that of organizational environment was collected for analysis. The findings suggest seven motives or the reasons responsible for the best performance measurement. The motives includes: competition, overall quality awards, nature of work, initiatives for improvement and technology awareness etc.

Brignall and Modell (2000) made multidimensional study on the issue of performance measurement. The study includes the role and measurement of key stakeholders of the organizations. Further, the study also compared the efficiency and effectiveness of performance of organizations in both public sector and private sector as well. The findings of the study revealed that for service related business the performance is heavy dependent upon the collaboration of three stakeholders such as the employees, the suppliers and the management. Besides to it the Measurement of Performance is a key factor with making certain your productive rendering associated with an organization's tactic.

Punniyamoorthy and Murali (2008) made comprehensive study to develop model of Balanced Score. The study was also aimed to suggest the benchmark to appraise the accomplishment of the goals set by organization. The study discussed and endorsed other models of Balanced Score and it also used the Preference theory for determining the weightings to be assigned to factors taken. By way of example, conventional fiscal analysis failed to take into account such critical specifics seeing that amounts of customer service, well-being staff, and industry discussed simply by section as well as other important factors which had an effect on a great organization's best good results.

The study was taken by Ittner, Larcker and Meyer (2003) required information from the successful firms in developing the model. The model suggests all required factors for consideration during the plan and implementation process. The study also provides reasonable weightings to be assigned for each factor during the process. It is usually of any kind of sole need or the particular aspirations with the prime management can adjust the particular success of the company. When each one of these are not supervised properly and also the linkages not really comprehended effectively, after that it may hold back your overall performance of an corporation. Therefore it will become very important with the administrators to offer the obvious understanding of the ultimate overall performance requirements your corporation has got to attain.

Amaratunga and Baldry (2003) conducted study to link the organizational performance with key indicators of performance and Balance Scorecard such as managerial behavior, management facilities, and financial measurement.. To attain the desired objective the Business must accept any processes for measuring the performance. Further, the benchmarking of standards which would help firms in making things correct and also in making the correct thing. Competition has turned into so powerful that managers have fewer times to react to market promptly. 
Bremser and Barsky (2004) made study to analyze the development in technology and the need for development in communication for performance related issues. The study suggested the manager to pact with an organizational commitment and that of reasonable steps for enhancing the performance. The study considered a tool to test and control the performance. That tool showed the concept of the BSC. The BSC was conceptualized with five indicators such as strategy, financial and operating controls. The study concluded that the operating factor has moderate impact on the performance. The financial aspect had significantly positive impact on the performance. The strategy factor played insignificant contribution for performance.

Bilderbeek (1999) made detailed study to establish proper model related to measuring the performance and the study also created link of performance with $\mathrm{R} \& \mathrm{D}$. The method of feed forward was introduced in organizations under study. The analysis was investigated with available feedback. The study concludes that there is strong need for a system to measure the performance such as Balanced Scorecard.

Voelker, Rakich and French (2001) made a study to investigate the role of measuring performance in the working organizations such as the Hospitals. The study includes various perspectives for measuring the performance such as operations, financial and strategies. The study endorsed that the measuring system such BSC has significant positive influence over the performance. The study concludes that the BSC is an essential tool for increasing the performance.

Kerssens, Drongelen and Cooke (1997) investigated the role of controlling system and the performance in the context of $\mathrm{R} \& \mathrm{D}$. various parameters for designing the measuring systems were made. The detail analysis highlighted the problems where the controls were weak. The study showed that performance is positively correlated with its measuring. Therefore, there should be a measuring system such as BSC. The study proposed a prototype of measuring system.

Tseng (2010) investigated evaluation system with multi-dimensions. The study designed a BSC system with attributes of multi-dimensions. The study considered four aspects of the BSC. There were 22 criteria discussed for the BSC. The results highlighted the significant impact of the BSC on the performance. The study concluded that multidimensional BSC was effective tool for both measuring as well as improving the performance. Further the very best supervision has to be capable to regularly keep track of your advancement intended for your success on the organizing targets to be able to make sure effective success on the techniques. When deciding to take any meaningful assessment, they must become having some aim measures to review your productivity on the firm using each of the size regarding its procedure. Human beings along with structural cash are usually the indication of your company's upcoming price along with power to make economic effects.

Zavadskas, Vainiūnas, Turskis and Tamošaitienè (2012) suggested in the study that handling $\mathrm{R} \& \mathrm{D}$ is critical for a lot of corporations to be able to pull through inside the competing and also energetic atmosphere. Therefore, decision-makers have always been engaged to the issues regarding choosing the best efficiency measures intended for R\&D. As a consequence, over the last couple of ages, the problem with the evaluate regarding $R \& D$ jobs features captivated more and more awareness, as a result bringing about a number of method in which range from any verification process to some more complex precise a single. 
Maltz, Shenhar and Reilly (2003) made study to evaluate the frameworks used for measuring the performance in various firms and to propose the effective tool for performance control. The study included 12 baselines for designing the system and that of five perspectives including financial and operations. The measuring system was testes in some firms to check the significance. The study suggested that performance was improved with usage of the designed measuring system for performance.

Eilat, Golany and Shtub (2008) investigated the evaluation model for the R \& D with multiple attributes for measurements. The framework of the BSC was designed. The study linked the BSC system in projects for R \& D to evaluate the performance. The evaluation was made in seven perspectives. The link was of the BSC with R \& D projects proved effective. The performance of the projects was significantly improved due to implementation of the BSC.

Cebeci (2009) made comprehensive study on the implementation of the BSC in the environment of the ERP. The study was longitudinal and complex. The sector of textile was taken for the study to carry out. The system of ERP was linked for performance measurement. Various factors were investigated to gauge the performance.

Dormio, Barbara Bigliardi (2010) Scrutinized and evaluated regarding exploration and also improvement (R\&D) jobs had always been quite hard. The part regarding $R \& D$ features was modified far in the past, moving by having a stage regarding isolation to some stage regarding integration within parallel merchandise improvement process. Moreover, $R \& D$ is becoming even more any proper purpose for your firms, currently being aligned correctly because of the pieces of the organization strategy. For that reason, R\&D is an integral subject for your firm's advancement strategy, and also requires an integrated method regarding rating in which examines each fiscal and also non-financial dividend.

The main aim of the study made by Turskis and Zavadskas (2011) is to evaluate how a BSC is used as well as may be used intended for R\&D pursuits, and also exclusively to create the suitable symptoms for every single perspective. That means the main trouble that you have numerous symptoms intended for examining this achievement of an organization in the extensive impression, yet in case all of us talk about R\&D pursuits it could be complicated to find the right kinds. The action is often a well-organized strategy of knowledge design, creation, diffusion, and also program, in which consists of advancement within controlled technological know-how, within administration measures, and also within cultural and also political programs. A few related studies include targeted mostly in work in completely new ventures whilst they've got provided much less awareness of this useful using this methods, after they will be in location.

Hoque and James (2000) made study to investigate the measures regarding R\&D efficiency can be employed intended for a number of requirements: intended for proper command, intended to justify the stuff for improving pursuits and for encouraging for performance. The study suggests need for benchmarking. The study concluded the strong need for the system such as the BSC for enhancing the improvement level.

\subsection{Hypotheses of the Study}

H1: Financial Perspective in balanced scorecard model has significant positive impact on Banks Performance. 
H2: Customer Perspective in balanced scorecard model has significant positive impact on Banks Performance.

H3: Internal Process perspective in balanced scorecard model has significant positive impact on Banks Performance.

H4: Learning and Growth Perspective in balanced scorecard model has significant positive impact on Banks Performance.

H5: Vision and Strategy Perspective in balanced scorecard model has significant positive impact on Banks Performance.

\section{RESEARCH METHODOLOGY}

\subsection{Method of Data Collection}

The data has been collected using primary source. The source of Data includes employees of Banks at middle level. A questionnaire has been designed to collect the required data. The questioner is close ended with 5 five options i.e. Strongly Disagree, Disagree, Neutral, Agree and Strongly Agree. Each option is coded with a value that shall be used in one sample test. The number starts from strongly disagree; given, disagree is given value 2. Similarly 3 is used for Neutral, 4 is assigned to agree and 5 for strongly agree.

\subsection{Sampling Technique}

Non Probability Sampling Technique is used to collect the data. A sample of 400 professional belonging to various Banks has been selected for selective survey interview. The range of survey was Karachi, Pakistan.

\subsubsection{Sample Size}

A sample of 400 professional belonging to various Banks has been selected for selective survey interview. The professionals includes; operation managers, senior managers, Treasury and Risk Analysts etc.

\section{3. $\quad$ Statistical Test applied}

The categorical data (on ordinal scale) which has been collected via questionnaire shall be statistically analyzed. Before applying statistical test the reliability test has been applied to test the reliability of data series. The OLS Regression Model has been applied after the satisfaction of reliability criteria of data series. In order to apply Regression model, the categorical data (on ordinal scale) has been converted into scale measurement. The procedure may be summarized as: the average of each 5 questions of related independent variable has been made to represent it as one variable and average of each question of dependant variable has also been made. 


\subsection{Research Model Developed}

Since this study investigates effect of various perspectives used in Balance Score Card on Bank's Performance. The Basic Regression Model is as:

$$
Y=\beta_{0}+\beta_{1} X_{1}+\beta_{2} X_{2}+\beta_{3} X_{3}+\ldots \ldots \ldots .+\mu
$$

This study requires developing a model to estimate the effect of Balance Score Card on Banks' Performance (BP).

We have taken following perspectives of our Balance Score Card which shall be used to test their effect on the Bank's Performance. Hence, these factors may be used as predictors in our Regression Model

Financial Perspective (FP)

Customer Perspective (CP)

Internal Control Perspective (ICP)

Learning and Growth Perspective (LGP)

Vision and Strategy Perspective (VSP)

Therefore, the required model shall become as follows:

$$
B P=\beta_{0}+\beta_{1} F P+\beta_{2} C P+\beta_{3} I C P+\beta_{4} L G P+\beta_{5} V S P+\mu
$$

Figure 1

Conceptual Model

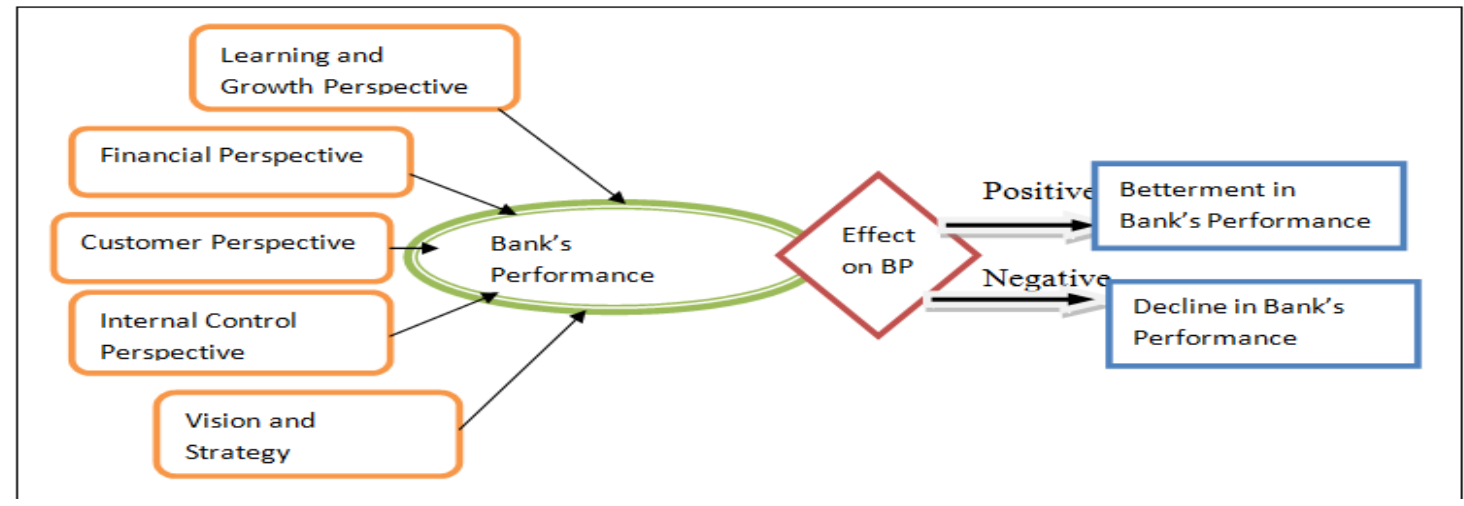

Source: Model Framework to Test the Influence of Balanced Scorecard on Bank Perormance

\section{RESULTS OF THE STUDY}

\subsection{Reliability and validity of Model: Interpretation of Reliability Test and ANOVA}

The reliability test is used to test the reliability of categorical data which shall then be applied as scale in Regression analysis. Table 1 shows the value of Cronbach's Alpha (0.69) which is more than 0.5 showing appropriate justification of the reliability of data series. Therefore the data series is reliable for further statistical analysis. 
Table 1

Reliability Test

\begin{tabular}{|l|l|}
\hline Reliability Statistics \\
\hline Cronbach's Alpha & N of Items \\
\hline 0.691 & 25 \\
\hline
\end{tabular}

The responses of survey were analyzed with T-test (one sample) using SPSS (19). The following regression Model has been applied for the statistical analysis:

$$
B P=\beta_{0}+\beta_{1} F P+\beta_{2} C P+\beta_{3} I C P+\beta_{4} L G P+\beta_{5} V S P+\mu
$$

The goodness fit and reliability of Model may be tested via ANOVA and the value of Adjusted R square. Table 2 shows that on average model provide reasonably good explanation (value of adjusted $\mathrm{R}$ square) which is up to $50 \%$. Where as table 3 shows the result of ANOVA test. The sig value is less than 0.05 as well as $F$ value (116) is also significant showing that ANOVA test is significant and hence the null hypothesis for equality of all means may be rejected. The ANOVA result signifies the model fit for Regression.

Table 2

Model Summary

\begin{tabular}{|l|l|l|l|}
\hline Model & R & & R Square \\
\hline & R & $\begin{array}{l}\text { Adjusted R } \\
\text { Square }\end{array}$ \\
\hline predictor: FP & 0.735163132 & 0.540464831 & 0.5024 \\
\hline
\end{tabular}

Table 3

ANOVA

\begin{tabular}{|l|l|l|l|l|l|}
\hline Model & Sum of Squares & df & $\begin{array}{l}\text { Mean } \\
\text { Square }\end{array}$ & F & Sig. \\
\hline Regression & 12.348 & 4 & 3.087 & 116.141 & \\
\hline Residual & 10.499 & 395 & 0.02658 & & 0.0001 \\
\hline Total & 22.847 & 399 & & & \\
\hline
\end{tabular}

Based on the results of ANOVA and Reliability test the Regression model may be applied. We paste here the Regression Model which has been developed for our study:

$$
B P=\beta_{0}+\beta_{1} F P+\beta_{2} C P+\beta_{3} I C P+\beta_{4} L G P+\beta_{5} V S P+\mu
$$

Table 4 provides the results of Regression model. The model to estimate the Bank performance due to efforts of Balance Score Card would be as follows:

$$
B P=3.999+0.244 F P+0.189 C P+0.099 I C P+0.137 L G P+0.06 S P
$$


The beta of only Vision and Strategy Perspective is insignificant since its sig value is more than 0.05 and $\mathrm{T}$ value $(0.968)$ is also insignificant. All other betas are significant. Therefore the final version of equation would be:

$$
B P=3.999+0.244 F P+0.189 C P+0.099 I C P+0.137 L G P
$$

The equation (and the results of Beta coefficients in table 4) depicts positive sign which endorses the positive effect of all four Perspectives of Balance Score Card on the functional performance in Banks.

Table 4

Regression Analysis

\begin{tabular}{|l|l|l|l|l|}
\hline \multirow{2}{*}{ Model } & $\begin{array}{l}\text { Unstandardized } \\
\text { Coefficients }\end{array}$ & $\begin{array}{l}\text { Standardized } \\
\text { Coefficients }\end{array}$ & \multicolumn{2}{|l|}{ criteria for Significance } \\
\cline { 2 - 6 } & B & Beta & T value & sig Value \\
\hline Constant & 3.999 & & 24.901 & 0.00 \\
\hline Financial Perspective & 0.244 & 0.224 & 4.681 & 0.001 \\
\hline Customer Perspective & 0.189 & 0.288 & 2.982 & 0.004 \\
\hline Internal Process Perspective & 0.099 & 0.224 & 2.276 & 0.025 \\
\hline $\begin{array}{l}\text { Learning and Growth } \\
\text { Perspective }\end{array}$ & 0.137 & 0.233 & 2.374 & 0.02 \\
\hline $\begin{array}{l}\text { Vision and Strategy } \\
\text { Perspective }\end{array}$ & 0.06 & 0.097 & 0.968 & 0.336 \\
\hline
\end{tabular}

$$
B P=\beta_{0}+\beta_{1} F P+\beta_{2} C P+\beta_{3} I C P+\beta_{4} L G P+\beta_{5} V S P+\mu
$$

H1: Financial Perspective in balanced scorecard model has significant positive impact on Banks Performance.

The sig value (0.001) beta coefficient of Financial Perspective (FP) is less than 0.05 which shows it significance. The above Regression equation shows that Bank Performance is positively affected by Financial Performance because the coefficient has positive sign; this justifies that first hypothesis of the study hypothesis is accepted.

H2: Customer Perspective in balanced scorecard model has significant positive impact on Banks Performance.

The test is significant for the beta coefficient of Customer Perspective (CP) since the sig value (0.004) of the model is less than 0.05; therefore, hypothesis is accepted which shows that there is significant relation between Customer Perspective (CP) and Bank Performance (BP). Moreover, the positive sign of beta coefficient justifies the presence positive influence of $\mathrm{CP}$ on Bank Performance. Therefore the second hypothesis is also accepted hence the Bank Performance is significantly and positively influenced by the customer perspective of balance score card. 
H3: Internal Process perspective in balanced scorecard model has significant positive impact on Banks Performance.

The sig value (0.025) of beta of the Internal Process Perspective (IPP) is less than 0.05 , the test is significant, hence the hypothesis is accepted which shows that there is significant effect of Internal Process Perspective (IPP) on Bank performance. Moreover the positive value of beta coefficient witnesses the positive influence of IPP on Bank Performance.

H4: Learning and Growth Perspective in balanced scorecard model has significant positive impact on Banks Performance.

The sig value (0.02) of Learning and Growth Perspective (LGP) is less than 0.05 which shows that the test is significant; therefore, hypothesis is accepted which shows that there is significant effect of LGP on Bank Performance (BP). The Bank Performance is, therefore significantly influenced by the growth Perspective (LGP) of balance score card.

H5: Vision and Vtrategy Perspective in balanced scorecard model has significant positive impact on Banks Performance.

The sig value (0.336) of beta of Vision and Strategy Perspective (VSP) is more than 0.05 which shows that the test is significant; therefore, hypothesis is rejected which shows that there is significant relation between learning and vision and strategy perspective (VSP) and Bank Performance (BP).

\section{DISCUSSION AND CONCLUSION}

\subsection{Discussion}

The results of the study have shown that four hypotheses out of five have been accepted. The respondents agreed that the financial perspective of the balance score card plays significant role for overall Bank Performance. The positive Beta of FP in regression equation further clarifies that financial perspective contributes positively in achieving the Banks' objectives. The respondents believe that when the management of the Bank sets some score card standards for financial performance and monitors their performance, it greatly influences the financial performance. Further, it was also agreed that customer satisfaction rises by developing model of Balance score card related to customers. Setting the standards for customer preferences, getting feedback from customers and continuous communication with customers pursue the customers to be loyal with Bank. The respondents believe that Bank Performance increases when the Standards of Balance Score Card are implemented successfully as well as continuously monitored. The customer satisfaction is core element in generating the revenue for the Banks, therefore it should be safeguarded. In addition to customer perspective, the employees' are the second stakeholders for Bank performance; their Training and Growth is highly essential. Therefore, the model of Score Card for Learning and Growth perspective appear to be desirable. This proposition also has been endorsed by the respondents. It was agreed that the Learning and Growth of the employees is another major contributor for achieving over all Bank performance. 
On the other side, another proposition was made that internal process control also take part in achieving the Bank performance. The survey conducted in banks showed significant impact of internal process control over the Bank Performance. The respondents believe that the internal process (IP) controls are reasonably good for monitoring any score card perspective. However, the IP controls have direct impact over the Bank performance.

The significant proposition made management scientists is that setting of vision and strategy play significant role in motivation and performance of the employee. This proposition has not been endorsed by the respondents in Banks. The respondents believe that setting of vision and endorsing the strategies may motivate employees but, the marginal performance due to vision and strategy model of score card is not so significant that it could contribute directly in Bank Performance.

\subsection{Conclusion}

It has been concluded based that the respondents believe that implementation of Balance score card models in Banks provide favorable outcomes. Especially the financial, internal control, learning and growth and customer perspectives have significant positive effect over the Bank's Performance.

It also has been concluded that Bank Performance is significantly improved due to implementation of Balance score card models in different perspectives. The four perspectives out of five: financial, customer, internal process and learning and growth perspective has remarkable contribution in improving Bank's overall performance. However, the vision and strategy perspective could have insignificant role in Bank's Performance.

\section{REFERENCES}

Amaratunga, D., \& Baldry, D. (2003). A conceptual framework to measure facilities management performance. Property management, 21(2), 171-189.

Amaratunga, D., Haigh, R., Sarshar, M., \& Baldry, D. (2002). Application of the balanced score-card concept to develop a conceptual framework to measure facilities management performance within NHS facilities. International Journal of Health Care Quality Assurance, 15(4), 141-151.

Banker, R. D., Chang, H., \& Pizzini, M. J. (2004). The balanced scorecard: Judgmental effects of performance measures linked to strategy. The Accounting Review, 79(1), 123.

Bilderbeek, J. (1999). R\&D performance measurement: more than choosing a set of metrics. R\&D Management, 29(1), 35-46.

Bremser, W. G., \& Barsky, N. P. (2004). Utilizing the balanced scorecard for R\&D performance measurement. R\&D Management, 34(3), 229-238.

Brignall, S., \& Modell, S. (2000). An institutional perspective on performance measurement and management in the 'new public sector'. Management Accounting Research, 11(3), 281-306.

Cebeci, U. (2009). Fuzzy AHP-based decision support system for selecting ERP systems in textile industry by using balanced scorecard. Expert Systems with Applications, $36(5)$. 
Eilat, H., Golany, B., \& Shtub, A. (2008). R\&D project evaluation: An integrated DEA and balanced scorecard approach. Omega, 36(5), 895-912.

Hoque, Z., \& James, W. (2000). Linking balanced scorecard measures to size and market factors: impact on organizational performance. Journal of management accounting research, 12(1), 1-17.

Ittner, C. D., Larcker, D. F., \& Meyer, M. W. (2003). Subjectivity and the weighting of performance measures: Evidence from a balanced scorecard. The Accounting Review, 78(3), 725-758.

Kerssens-van Drongelen, I. C., \& Cooke, A. (1997). Design principles for the development of measurement systems for research and development processes. R\&D Management, 27(4), 345-357.

Malmi, T. (2001). Balanced scorecards in Finnish companies: a research note.Management Accounting Research, 12(2), 207-220.

Maltz, A. C., Shenhar, A. J., \& Reilly, R. R. (2003). Beyond the Balanced Scorecard:: Refining the Search for Organizational Success Measures. Long Range Planning, 36(2), 187-204.

Neely, A. (1999). The performance measurement revolution: why now and what next?. International Journal of Operations \& Production Management, 19(2), 205-228.

Punniyamoorthy, M., \& Murali, R. (2008). Balanced score for the balanced scorecard: a benchmarking tool. Benchmarking: An International Journal, 15(4), 420-443.

Tseng, M. L. (2010). Implementation and performance evaluation using the fuzzy network balanced scorecard. Computers \& Education, 55(1), 188-201.

Turskis, Z., \& Zavadskas, E. K. (2011). Multiple criteria decision making (MCDM) methods in economics: an overview. Technological and Economic Development of Economy, (2), 397-427.

Voelker, K. E., Rakich, J. S., \& French, G. R. (2001). The balanced scorecard in healthcare organizations: a performance measurement and strategic planning methodology. Hospital topics, 79(3), 13-24.

Zavadskas, E. K., Vainiūnas, P., Turskis, Z., \& Tamošaitienè, J. (2012). Multiple criteria decision support system for assessment of projects managers in construction. International Journal of Information Technology \& Decision Making, 11(02), 501520. 